\title{
Performances comparées de systèmes de culture destinés à I'alimentation animale en France et aux États-Unis
}

\author{
Benoit CARROUÉE ${ }^{1}$ \\ Marc BERRODIER ${ }^{2}$ \\ Franck WIACEK ${ }^{2}$ \\ Marie-Hélène JEUFFROY 3 \\ ${ }^{1}$ UNIP, \\ Union Nationale Interprofessionnelle \\ des plantes riches en Protéines, \\ 12 av. George V, \\ 75008 Paris \\ $<$ b.carrouee@unip.fr> \\ ${ }^{2}$ ARVALIS - Institut du végétal, \\ 91720 Boigneville \\ ${ }^{3}$ UMR Agronomie INRA-AgroParisTech, \\ 78850 Thiverval-Grignon
}

\section{Made in USA : le couple maïs-soja}

Base des rations animales pour porcs et volailles, le couple maïs-soja est dominant dans les systèmes de culture de pays comme les ÉtatsUnis ou le Brésil. La rotation simple sur deux ans « maïs-soja » y est répandue et semble durable sur le plan agronomique : le soja constitue un précédent favorable pour le maïs et les deux cultures s'accommodent d'un retour tous les 2 ans sur la même parcelle. Cette rotation peut être très productive dans des sols profonds et sous un climat chaud et pluvieux en été. Le rendement du maïs est environ 3 fois plus élevé que celui du soja, mais nécessite plus d'intrants (azote et charges de mécanisation). Ainsi, dans l'lowa, l'État où l'on observe les plus grandes surfaces et les meilleurs rendements en maïs et en soja aux États-Unis, le rendement moyen du maïs, en majeure partie non irrigué, atteint en moyenne 108 q/ha et celui du soja $33 \mathrm{q} /$ ha (tableau 1 ).

Sur le plan nutritionnel, après trituration du soja, la production correspondant à cette succession de cultures, donne environ $80 \%$ de maïs, $20 \%$ de tourteaux de soja plus de l'huile destinée à l'alimentation humaine ou à la fabrication de biocarburants. Cette proportion « $80 \%$ de maïs $+20 \%$ de tourteaux de soja » correspond bien aux besoins d'un porc

\begin{abstract}
The combination of corn, peas and rapeseed, three crops well adapted to soil and climatic European conditions, can form the basis of balanced rations for pig farms. Despite production costs significantly higher, from the farm than those permitted by cropping systems based on corn and soybeans in the US, local supplies of protein-rich materials (PRM) is competitive economically, because of transportation costs and tariff protection on cereals in Europe. However, the supply of local origin PRM is far from meeting the needs of industry feed since nearly half of those needs is imported. This deficit ultimately returns to the question of the balance of French and European crop rotations, showing a surplus of grain and a protein déficit. Various case studies suggest that rebalancing rotations would be possible to improve the local supply and the economic and environmental performance of cropping systems corresponding. This would occur even in areas with already a large enough diversification of crops as Picardy and the lle de France, analyzed in this article.
\end{abstract}

Key words: crop rotation, animal feeding, competitiveness, pea, rapeseed, soyabean

en croissance (tableau 2) et assez bien à celui $d^{\prime}$ un poulet de chair à vitesse de croissance intermédiaire. Pour ajuster cette ration simple à deux constituants, de petites quantités d'acides aminés de synthèse et un complément minéral et vitaminé suffisent.

\section{En Europe : des systèmes plus diversifiés}

En France et dans la plupart des pays européens, le couple de culture maïs-soja n'est guère adapté : mis à part quelques régions comme la plaine du Pô ou de l'Alsace par exemple, le climat n'est pas assez chaud et/ou pas assez pluvieux en été. En outre, le rapport de prix maïs/ soja, plus favorable au maïs qu'au soja à l'intérieur des frontières de l'UE que sur le marché mondial, pousse à la monoculture de maïs plus qu'à la succession maïs-soja dans les quelques régions européennes qui seraient adaptées. Les rations animales européennes sont généralement à base de céréales à pailles produites à proximité (blé, orge, triticale), de tourteaux d'oléagineux (principalement issu de soja importé ou de colza européen) et, lorsque l'offre n'est pas limitante, de protéagineux, (principalement le pois). Pour l'approvisionnement de l'industrie de l'alimentation animale, les systèmes de production à base de cultures d'hiver ou de printemps - blé, orge, colza et pois -, adaptées aux climats océaniques ou continentaux d'Europe ou du Canada, constituent le pendant des systèmes de production à base de cultures d'été - maïs et soja - adaptés aux climats tropicaux.

La raison d'être de ces systèmes de production plus diversifiés en Europe qu'aux États-Unis répond à la fois à une nécessité agronomique et à une nécessité nutritionnelle :

- en alimentation animale, la complémentarité du pois ou de la féverole avec le colza a été évoquée dans les articles précédents : du fait de leurs limites d'incorporation et de leurs profils en acides aminés, et contrairement au tourteau de soja, ni les tourteaux de colza ou tournesol, ni le pois ou la féverole ne peuvent à eux seuls complémenter des rations porcs ou volailles à base de céréales : il faut combiner pois et tourteau de colza par exemple pour les rations porcs et féverole et tourteau de tournesol par exemple pour des volailles ${ }^{1}$;

\footnotetext{
${ }^{1}$ Cette complémentarité vaut pour les porcs, les volailles à croissance intermédiaires (> 52 jours) et les pondeuses. En revanche, pour les ruminants, moins sensibles à l'équilibre en acides aminés, le tourteau de colza peut constituer à lui seul la source de MRP ; et pour les volailles de chair à croissance rapide (42 jours), la combinaison de matières premières « européennes » n'est pas assez concentrée en énergie et en protéines pour maintenir les vitesses de croissance permises par la combinaison maïs-soja.
} 
Tableau 1. Surfaces et rendements moyens en Picardie et dans I'lowa.

\begin{tabular}{|c|c|c|c|c|c|}
\hline \multicolumn{3}{|c|}{ Picardie, source Agreste/Unip, } & \multicolumn{3}{|c|}{$\begin{array}{l}\text { lowa, source USDA, moyenne } \\
2005-2009\end{array}$} \\
\hline $\begin{array}{l}\text { Picardie, } \\
\text { source } \\
\text { Agreste/Unip }\end{array}$ & $\begin{array}{l}\text { Surfaces } \\
\text { ( } 1000 \text { ha) } \\
\text { en } 2010\end{array}$ & $\begin{array}{l}\text { Rendement } \\
\text { (q/ha) } \\
\text { moyenne } \\
2006-2010\end{array}$ & & $\begin{array}{l}\text { Surfaces } \\
\text { (1 } 000 \text { ha) }\end{array}$ & $\begin{array}{l}\text { Rendement } \\
\text { (q/ha) }\end{array}$ \\
\hline Blé tendre d'hiver & 517 & 84 & Maïs & 5257 & 108 \\
\hline Orge d'hiver & 70 & 80 & Soja & 3879 & 34 \\
\hline Orge de printemps & 40 & 68 & & & \\
\hline Maïs (non irrigué) & 50 & 92 & & & \\
\hline Colza & 112 & 35 & & & \\
\hline Pois & 34 & 50 & & & \\
\hline Féverole & 41 & 49 & & & \\
\hline
\end{tabular}

Tableau 2. Exemple de rations simples pour porcs charcuiers. Source : Céréopa/Unip.

\begin{tabular}{|llll|}
\hline $\begin{array}{l}\text { Type } \\
\text { de ration }\end{array}$ & Blé-Soja & $\begin{array}{l}\text { Blé-Pois- } \\
\text { Colza }\end{array}$ & $\begin{array}{l}\text { Maïs- } \\
\text { soja }\end{array}$ \\
\hline EN en MJ & 9,9 & 9,6 & 10,3 \\
\hline$\%$ MAT & 16,3 & 16,5 & 15,9 \\
\hline Blé & $82 \%$ & $56 \%$ & \\
\hline Maïs sec & & & $78 \%$ \\
\hline Pois & & $30 \%$ & \\
\hline Tt Soja 48 & $16 \%$ & & $20 \%$ \\
\hline Tt Colza & & $12 \%$ & \\
\hline Lysine & $0,34 \%$ & $0,23 \%$ & $0,35 \%$ \\
\hline Méthionine & $0,04 \%$ & $0,06 \%$ & $0,05 \%$ \\
\hline Thréonine & $0,11 \%$ & $0,10 \%$ & $0,10 \%$ \\
\hline Tryptophane & $0,00 \%$ & $0,02 \%$ & $0,00 \%$ \\
\hline $\begin{array}{l}\text { Prix de la } \\
\text { ration en } € / t \\
\text { (moyenne } \\
\text { 2009/2010) }\end{array}$ & 165,4 & 163,8 & 173,9 \\
\hline
\end{tabular}

NB : respect des normes CORPEN pour azote et phosphore (ajout de $500 \mathrm{U}$ de phytase microbienne pour minimum $1,75 \mathrm{~g} / \mathrm{kg} P$ dig et maxi $4,8 \mathrm{~g} / \mathrm{kg} P$ total) ; rations équilibrées en acides aminés digestibles/ énergie nette.

- sur le plan agronomique, des rotations faisant revenir soit du pois soit du colza tous les 2 ans sur une même parcelle en alternance avec du blé, comme dans la rotation maïs-soja, ne seraient pas durables : certains problèmes de mauvaises herbes, de maladies racinaires ou d'insectes deviendraient difficilement gérables, même avec un recours accru aux produits phytosanitaires. Chacune de ces deux cultures est un bon précédent pour le blé et contribue aux performances de celui-ci, mais il est préférable de les faire alterner et de les insérer dans des rotations d'au moins 5 ans ${ }^{2}$.

\section{Compétitivité d'une succession européenne colza-blé-pois-blé}

Quelle est la compétitivité d'une succession européenne colza-blé-pois-blé, comparativement à celle de la succession maïs-soja aux États-Unis pour répondre aux besoins de I'alimentation animale? Pour apporter des éléments de réponse, nous proposons d'analyser les performances nutritionnelles de systèmes de culture dans les régions les plus productives de part et d'autre de l'Atlantique: I'lowa évoqué plus haut, et le bassin parisien en France.

La Picardie et I'lle-de-France, dans le Bassin parisien, sont parmi les régions les plus productives de France et d'Europe sur le plan des rendements : I'étendue et l'épaisseur la couche de limons sur des substrats filtrants y donnent des sols fertiles, et le climat océanique permet de fortes croissances au printemps. Ces régions présentent la particularité d'avoir une large palette de cultures et donc des rotations relativement diversifiées, comparées à d'autres régions françaises ou à celle du Corn Belt amé-

\footnotetext{
${ }^{2}$ Pour le pois, une fréquence de retour tous les 4 ans est considéré comme trop rapide et il est conseillé soit d'alterner pois et féverole dans les régions où ces deux protéagineux sont possibles, soit d'insérer la succession pois-blé-colza-blé dans une rotation plus longue.
}

ricain (dont l'lowa est l'État le plus productif). Cela s'explique par l'abondance de « cultures industrielles » comme la betterave, la pomme de terre, l'orge brassicole ou les légumes de conserve, liées à l'existence d'un tissu agroindustriel dense dans ces régions (tableau 3). En outre, comme ailleurs en France, en année moyenne, environ la moitié des blés tendres sont destinés à la meunerie en France ou à l'exportation, et l'autre moitié à l'alimentation animale, à l'amidonnerie ou à l'industrie de l'éthanol en France ou dans le Bénélux.

Au global, l'assolement moyen de l'ensemble Picardie + lle-de-France pourrait être représenté par une rotation sur 9 ans de type: Betterave-Blé-Orge-Colza-Blé-Protéagineux-BléPomme de terre-Blé-Autre culture (maïs, lin ou légume de conserve)-Blé (tableau 4). Dans cette rotation, plus de la moitié des cultures sont destinées à I'alimentation humaine (meunerie, sucrerie, féculerie, brasserie, conserverie...). Le segment de rotation Colza-Blé-Pois-Blé correspondant à la partie destinée à l'alimentation animale et - pour la partie huile extraite du colza - à la production d'huile alimentaire ou de biocarburant.

Cette rotation type peut se rencontrer sur des exploitations disposant de quotas betteraviers et de contrats de cultures industrielles représentant environ chacun $10 \%$ de leur sole. En pratique, on rencontre des exploitations avec une plus forte proportion de cultures industrielles, et donc moins de place pour le colza et les protéagineux (par exemple dans les régions de très bonnes terres comme le Santerre), ou des exploitations avec peu de cultures industrielles et donc essentiellement du colza et du pois en dehors des céréales à pailles. On retrouve ces dernières principalement dans les secteurs de moins bonnes terres comme le Plateau picard. Les rendements moyens observés en moyenne de 2006 à 2010 en Picardie sont de 84 g/ha pour le blé, $35 \mathrm{q} / \mathrm{ha}$ pour le colza et $50 \mathrm{q} / \mathrm{ha}$ pour le pois (tableau 1). La productivité brute d'une sole comportant $50 \%$ de blé, $25 \%$ de colza et $25 \%$ de pois, correspondant à un segment de rotation « pois-blé-colza-blé », est de $6 \mathrm{t} / \mathrm{ha}$ de matières premières en moyenne en Picardie. C'est environ $10 \%$ de moins que celle d'une sole comportant $50 \%$ de maïs et $50 \%$ de soja dans I'lowa (tableau 5). Cette sole « picarde » produit plus d'huile (+ $30 \%)$ mais moins de nutriments pour l'alimentation animale : - $15 \%$ pour l'énergie nette porc, et - $19 \%$ pour les protéines brutes.

En revanche, l'équilibre des acides aminés importants, en $\%$ de la protéine, est très proche dans les deux systèmes : colza et pois compensent leurs faiblesses respectives en lysine et en acides aminés soufrés (méthionine + cystine), et le blé, nettement plus riche en tryptophane que le maïs, compense leur 
Tableau 3. Surfaces des différentes grandes cultures en Picardie + lle de France, en ha, en 2006. Source: Agreste.

\begin{tabular}{|c|c|c|c|c|c|c|c|c|c|c|c|}
\hline & Céréales & $\begin{array}{l}\text { dont Blé } \\
\text { tendre }\end{array}$ & $\begin{array}{l}\text { dont } \\
\text { Orges }\end{array}$ & $\begin{array}{l}\text { dont Maïs } \\
\text { grain et } \\
\text { ensilage }\end{array}$ & $\begin{array}{l}\text { Oléagineux } \\
+ \text { «gel } \\
\text { industriel " } \\
\text { (princ. } \\
\text { Colza) }\end{array}$ & $\begin{array}{l}\text { Protéagi- } \\
\text { neux (pois } \\
\text { + féverole) }\end{array}$ & $\begin{array}{l}\text { Plantes } \\
\text { à fibres }\end{array}$ & $\begin{array}{l}\text { Betteraves } \\
\text { yc bio- } \\
\text { carburant }\end{array}$ & $\begin{array}{l}\text { Pomme } \\
\text { de terre } \\
\text { (yc fécule) }\end{array}$ & $\begin{array}{l}\text { Autres } \\
\text { cultures } \\
\text { non aidées }\end{array}$ & $\begin{array}{l}\text { Total } \\
\text { cultures } \\
\text { arables }\end{array}$ \\
\hline ha & 1055754 & 747751 & 180431 & 108687 & 185481 & 102392 & 13908 & 175528 & 43653 & 46136 & 1622852 \\
\hline$\%$ total & $65 \%$ & $46 \%$ & $11 \%$ & $7 \%$ & $11 \%$ & $6 \%$ & $1 \%$ & $11 \%$ & $3 \%$ & $3 \%$ & $100 \%$ \\
\hline
\end{tabular}

Tableau 4. Exemple d'une rotation théorique sur 9 ans : Betterave sucrière/Blé/Orge bras./Colza/Blé/PdT, Maïs, ou Lin/Blé/Pois/Blé

\begin{tabular}{|lll|}
\hline $\begin{array}{l}\text { Assolement correspondant à cette } \\
\text { rotation de } \mathbf{9} \text { ans }\end{array}$ & Culture & $\begin{array}{l}\text { Moyenne Picardie + } \\
\text { Ile de France }\end{array}$ \\
\hline Blé & $44 \%$ & $46 \%$ \\
\hline Orge & $11 \%$ & $11 \%$ \\
\hline Betterave & $11 \%$ & $11 \%$ \\
\hline Oléagineux & $11 \%$ & $11 \%$ \\
\hline Protéagineux & $11 \%$ & $6 \%$ \\
\hline 1Pomme de terre, Maïs ou Lin & $11 \%$ & $11 \%$ \\
\hline total & $100 \%$ & $96 \%$ \\
\hline dont cultures valorisées en alimentation animale & $44 \%$ & \\
\hline
\end{tabular}

* Dont la moitié est utilisée en alimentation animale et l'autre en meunerie.

Tableau 5. Productivité comparée de l'assolement « Picardie » avec l'assolement « lowa ».

\begin{tabular}{|c|c|c|c|c|}
\hline \multicolumn{2}{|c|}{ Productivité globale par ha } & \multirow{2}{*}{$\begin{array}{l}\text { Picardie } \\
\text { colza- } \\
\text { blé-pois-blé }\end{array}$} & \multirow{2}{*}{$\begin{array}{l}\text { lowa } \\
\text { maïs-soja }\end{array}$} & \multirow{2}{*}{$\begin{array}{l}\text { Ratio Picardie/ } \\
\text { Iowa }\end{array}$} \\
\hline & Rotation & & & \\
\hline \multirow{5}{*}{$\begin{array}{l}\text { Quantités produites } \\
\text { en t/ha }\end{array}$} & Total en $t$ & 6,4 & 7,1 & $89 \%$ \\
\hline & Blé ou maïs & 4,2 & 5,4 & \\
\hline & Pois & 1,3 & & \\
\hline & Tt de colza ou de soja & 0,53 & 1,43 & \\
\hline & Huile colza ou de soja & 0,35 & 0,27 & $130 \%$ \\
\hline \multirow{6}{*}{$\begin{array}{l}\text { Production alimentaire } \\
\text { par ha hors huile }\end{array}$} & EN porc en $\mathrm{GJ} / \mathrm{ha}$ & 61 & 72 & $85 \%$ \\
\hline & Protéines en kg/ha & 881 & 1084 & $81 \%$ \\
\hline & lysine (en kg/ha) & 41 & 53 & $79 \%$ \\
\hline & $\begin{array}{l}\text { Méthionine + Cystine } \\
(\mathrm{kg} / \mathrm{ha})\end{array}$ & 32 & 39 & $82 \%$ \\
\hline & Thréonine (en kg/ha) & 31 & 41 & $75 \%$ \\
\hline & Tryptophane (en kg/ha) & 10 & 11 & $88 \%$ \\
\hline
\end{tabular}

relative faiblesse vis-à-vis du soja. Les besoins en acides aminés de synthèse pour ajuster parfaitement les apports en fonction des besoins du porc et respecter les «normes Corpen » en de I'alimentation animale, est donc lié à une productivité globale par hectare plus faible et non pas à la valeur nutritionnelle des graines : on peut se passer de soja. En outre, le système picard présente des coûts de production plus élevés liés à une consommation plus importante en engrais azotés (moins forte proportion de légumineuses) et de charges de mécanisation du fait de structures d'exploitation plus petites (Darracq et al., 1998). Pour les mêmes raisons, les bilans énergie et gaz à effet de serre, pour les matières premières à la sortie de l'exploitation, sont moins favorables.

Malgré ces handicaps de productivité et de coûts de production des matières premières européennes, les coûts de transport pour le soja et les droits de douane à l'importation pour le maïs (Carrouée et Coléou, 1996) font qu'une ration porc équilibrée à base de matières premières de proximité blé-pois-colza est compétitive par rapport à des rations recourant largement aux produits importés: dans l'exemple du contexte de prix moyen rendus Bretagne en 2009-2010, elle est légèrement moins chère qu'une ration composée uniquement avec du blé et du tourteau de soja, et nettement moins chère qu'une ration composée uniquement avec du maïs et du tourteau de soja (tableau 2).

Les voies d'amélioration de la compétitivité économique et environnementale du système français pour I'alimentation animale sont donc très classiques : augmentation des rendements et/ou diminution de charges de mécanisation et de fertilisation azotée.

Si les systèmes de culture picards, et encore plus ceux des autres régions françaises et européennes ne permettent pas d'approvisionner suffisamment l'industrie de I'alimentation animale en MRP, c'est la conséquence d'une disproportion entre les assolements de grande culture et les besoins de ce secteur (Carrouée et al., 2000). Ce déséquilibre conduit à importer beaucoup de soja et à exporter beaucoup de céréales.

La rotation type sur 9 ans prise comme exemple au tableau 4 est représentative de l'assolement moyen Picardie + lle-de-France, sauf dans le cas des protéagineux : elle en comporte envi- 
Tableau 6. Proportion des blés avec un précédent blé ou orge dans les différentes petites régions agricoles de Seine-et-Marne.

\begin{tabular}{|c|c|c|c|c|c|c|c|c|}
\hline $\begin{array}{l}\text { Total } \\
\text { Seine-et-Marne }\end{array}$ & $\begin{array}{l}\text { Bassée } \\
\text { ou Basse seine }\end{array}$ & $\begin{array}{l}\text { Brie } \\
\text { boisée }\end{array}$ & $\begin{array}{l}\text { Brie } \\
\text { centrale }\end{array}$ & $\begin{array}{l}\text { Brie } \\
\text { champennoise }\end{array}$ & $\begin{array}{l}\text { Brie } \\
\text { laitière }\end{array}$ & $\begin{array}{l}\text { Brie } \\
\text { française }\end{array}$ & $\begin{array}{l}\text { Bocage } \\
\text { gatinais }\end{array}$ & Gatinais \\
\hline $20 \%$ & $23 \%$ & $19 \%$ & $15 \%$ & $17 \%$ & $17 \%$ & $15 \%$ & $23 \%$ & $33 \%$ \\
\hline
\end{tabular}

Source : Schott et al., communication personnelle d'après les données Terruti de 1992 à 2003.

ron deux fois plus que la moyenne actuelle. Pourtant, ce sont deux des régions françaises où la part de protéagineux est la plus significative. C'est un constat bien connu : les protéagineux sont sous-représentés dans les assolements par rapport à la demande potentielle du marché.

La question de fond, pour accroître l'approvisionnement local en MRP de l'industrie de I'alimentation animale, reste la suivante : est-il possible d'accroître la proportion de protéagineux dans les assolements de grandes cultures sans dégrader les performances économiques des exploitations agricoles?

De nombreuses études économiques d'optimisation d'assolements ont été réalisées, pour différentes régions françaises, en partenariat entre I'Unip et le Pôle Économie d'ArvalisInstitut du végétal (Carrouée, 2004 ; Morice, 2004 ; Dubois, 2007b). On peut en tirer quelques tendances générales :

- La substitution de cultures industrielles sous quota ou sous contrat, type betterave, légumes ou pomme de terre par une autre tête d'assolement n'est en général pas rentable. On considérera donc la part de ces cultures dans les assolements comme une constante déterminée par les volumes de quotas ou de contrats. - Les blés assolés et, dans une moindre mesure, les orges brassicoles, présentent les meilleures marges après celles des cultures industrielles : pour être rentable, l'introduction de surfaces supplémentaires de protéagineux ou d'oléagineux ne doit pas se faire à leur détriment.

- En revanche, les blés sur blé ou les orges fourragères peuvent être diminués au profit du pois ou du colza. Dans les contextes de prix moyens des 5 dernières années, cela se traduit par une légère amélioration de la marge nette pour le producteur (Berrodier, 2010). Les contextes de flambée du prix des céréales comme celle de 2007-2008 et celle de ce début de campagne 2010-2011 constituent une exception où des blés sur blé peuvent paraître temporairement plus rentables

En outre, l'introduction de pois dans des rotations à base de céréales à pailles et de colza se traduit aussi par une amélioration des performances environnementales, particulièrement pour la consommation d'énergie fossile et les émissions de gaz à effet de serre (MunierJolain, 2003 ; Dubois, 2007).
L'abondance relative des blés sur blés en France, y compris dans ces régions de cultures diversifiées, constitue une question qui mériterait d'être approfondie. L'exploitation des statistiques pluriannuelles (1992 à 2003) de I'enquête Terruti du ministère de l'Agriculture montre que $20 \%$ des blés de Seine-et-Marne sont implantés après un autre blé (ou une orge). Cette proportion est significative dans toutes les petites régions de ce département : elle va de 15 à $33 \%$ (tableau 6). Cela représente près de $9 \%$ de la sole totale de grandes cultures, soit presque autant que la part actuelle d'oléagineux et nettement plus que la part actuelle des protéagineux.

Un blé sur blé produit en moyenne $8 \mathrm{q} / \mathrm{ha}$ de moins qu'un blé de pois ou de colza (Schneider et al., 2009). II nécessite une fertilisation azotée et parfois une protection phytosanitaire renforcée. Dans les rotations déjà chargées en cultures d'automne, les blés sur blé renforcent les problèmes de désherbage et de risque d'apparition de résistance. Ils sont donc nettement moins rentables que des blés assolés.

Sauf contexte exceptionnel de prix, l'insertion d'un pois ou d'un colza entre deux blés dans des rotations qui comportent des blés sur blés, avec l'hypothèse de rendements conformes à la moyenne locale, améliore légèrement la marge d'exploitation et renforce sa durabilité sur le plan agronomique et environnemental. Diverses raisons peuvent expliquer cette part importante de blé sur blé, non justifiée par des calculs d'optimisation d'assolements : simplification du travail, en particulier pour les très petites structures d'exploitation, présence de sols difficiles à cultiver dans lesquels les blés se comportent relativement mieux que d'autres cultures, moindre variabilité des rendements que ceux du pois ou du colza... Mais on ne peut pas écarter I'hypothèse du poids des habitudes ni celle d'une estimation biaisée de la rentabilité des cultures, liée à des comparaisons de marges brutes par culture et non pas par rotations/assolements.

Pour autant, I'enjeu de l'optimisation des assolements n'est pas le principal levier pour améliorer les performances économiques des systèmes de culture français. Une modification substantielle des assolements dans le sens d'un tel rééquilibrage ne pourrait se produire de façon significative qu'avec des facteurs exogè- nes à l'exploitation. II y a, dans la possibilité $d$ 'insérer des oléagineux ou des protéagineux au détriment des blés sur blé (et en renforçant la part relative des blés assolés) une marge de manœuvre potentielle pour améliorer à la fois l'approvisionnement en MRP d'origine locale pour l'industrie de I'alimentation animale et améliorer les performances économiques et environnementales des systèmes de cultures correspondants.

\section{RÉFÉRENCES}

Berrodier M. Intérêt économique des pois et féveroles dans les assolements de différentes régions françaises. Journées résultats Arvalis, 12 octobre 2010, Paris.

Carrouée $B$, Coléou J. Matières riches en protéines: les MRP, les protéagineux et l'Europe. Perspectives Agricoles 1996 ; (219) : 16-20.

Carrouée B, Gent GP, Summerfield RJ. Production and uses of grain legumes in the European Union. In : Knight $\mathrm{R}$, ed. Linking research and marketing opportunities for pulses in the 21st century. Kluwer Academic Press, 2000 : 79-97.

Carrouée B. L'intérêt économique des rotations diversifiées. Perspectives Agricoles 2004 ; (303) : 12-5.

Darracq S, Carrouée B, Cottart J, Lemaitre G. Production de protéines et d'énergie: comparaison Picardie-lllinois » Perspectives agricoles 1998 ; (237) : 26-8.

Dubois G. Rotation des cultures - Le pois s'affirme comme un atout pour l'environnement. Perspectives Agricoles 2007 ; (330) : 16-7.

Dubois G. Quantifier économiquement les intérêts agronomiques des protéagineux » Perspectives Agricoles 2007 ; (336) : 66-9.

Morice G. Compétitivité du pois et de la féverole dans les assolements de grandes cultures en France $" 4^{\circ}$ rencontre annuelle protéagineux. Arvalis-Unip 2004 ; janvier 2004.

Munier-Jolain N, Carrouée B. Quelle place pour le pois dans une agriculture respectueuse de l'environnement? Argumentaire agri-environnemental. Cahiers Agricultures $2003 ; 12: 111-20$.

Schneider A, Ballot R, Carrouée B, Berrodier M. Rentabilité des protéagineux dans la rotation - Quelle valeur économique pour l'effet du précédent? Perspectives Agricoles 2009 ; (360) : 6-11. 